\title{
Multi Variable Empirical Formula for SFRC Compressive, Tensile, And Shear Strength
}

\author{
Sheikha Mohammed AL-Shukaili ${ }^{1}$, Qadir Bux alias Imran Latif ${ }^{2}$
}

\begin{abstract}
Steel fiber-reinforced concrete (SFRC) is a cementations material reinforced with discrete fiber. Since 4 decades SFRC mechanical properties has been investigated and used as a construction material for different civil engineering projects such as concrete pavements, etc. A number of studies have demonstrated the technical merits and de-merits of SFRC over conventional concrete. Different types of steel fiber can be used as steel fiber reinforcement in concrete, such as plain, hooked, crimped and twisted etc. Each of them has different effects on the concrete depended on its shape physical and mechanical properties. In this paper new multivariable empirical formulas have been developed for compressive, tensile and shear strength of SFRC. It is found that new developed equation based on multiple variables predicts good results in comparison with experimental data.
\end{abstract}

Keywords-SFRC, Empirical, Steel fiber, Multiple Variable, Compressive, Shear, Tensile.

\section{INTRODUCTION}

Concrete is the most widely used material in the construction industry, and a great deal of attention has been paid to its proper use to perform its structural function and maintain appearance. The two basic types of problems with concrete can be categorized as structural strength and appearance. Concrete must have certain specified strengths to do its job as a structural item and these strengths are specified by the design engineers. Strength of concrete is related to its mix design and specifically the water/cement ratio. Other items of strength include aggregate maximum size and aggregate type.

SFRC namely Steel Fiber Reinforced Concrete is a composite material made of hydraulic cements, water, fine and coarse aggregate and small fibers. It may also contain pozzolans and admixtures commonly used with conventional concrete. According to ASTM specifications all admixtures used in concrete are suitable for use in SFRC. Because of the vast improvements achieved by the addition of fibers to concrete, there are several applications where Fibers Reinforced Concrete (FRC) can be intelligently and usefully used.[1]

Once failure is initiated, concrete is characterized by brittle failure which is the nearly complete loss of loading capacity. This characteristic, which limits the application of the material, can be overcome by the inclusion of a small amount of short randomly distributed fibers (steel, glass, synthetic and natural) and can be practiced among others that remedy weaknesses of concrete, for example low growth resistance, high shrinkage

\footnotetext{
${ }^{1,2}$ Department of Civil and Environmental Engineering, College of Engineering, University of Nizwa (UoN),

P. O Box 33, P C 616, Initial Campus at Birkat al Mouz, Nizwa, Oman
}

cracking, low durability, etc. Steel fiber reinforced concrete (SFRC) has the ability of excellent tensile strength, flexural strength, shock resistance, fatigue resistance, ductility and crack arrest. [1]

Hence, in this paper multivariable empirical equations are developed of SFRC to calculate compressive strength, shear strength, and tensile strength.

\section{Methodology}

The methodology adopted in the present study the developed of empirical equation of steel fibre reinforcement concrete (SFRC). The research starts by interdiction talking about RFC. Secondary data reviewed initially through the technical and paper research, and thesis. To aid the search, a table of key terms will be constructed and the sources located are correlated with this. A secondary cross-reference table are developed so that data can be viewed from different perspectives. After collection of data, analyses to examine how multiple independent variables are related to a dependent variable. Once it is identified how these multiple variables relate to dependent variable, information taken about all of the independent variables and used it to make much more powerful and accurate predictions about why things are the way they are. This latter process is called "Multiple Regression". Multiple Regressions will be used to develop of new empirical equations. Table: 1 show used different variables to developed empirical equations of mechanical strength of SFRC and the below Fig.1 shown the steps of paper work .

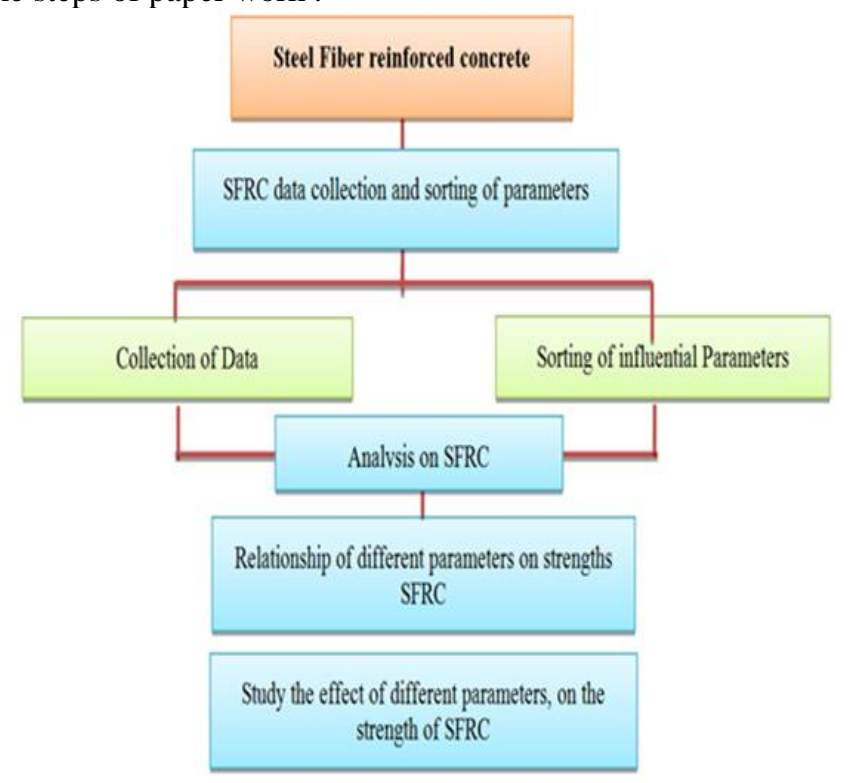

Fig.1: Flow chart for the paper 
TABLE I: DATA USED TO DEVELOPED EMPIRICAL EQUATIONS OF MECHANICAL STRENGTH OF SFRC

\begin{tabular}{|l|l|}
\hline Experimental Data & Range of Data \\
\hline Steel fiber percentage & $0-3 \%$ \\
\hline Cement content & $109-460$ \\
\hline Aggregate Content & $300-400$ \\
\hline Water cement ration & $0.11-0.5$ \\
\hline Shape of steel fiber & Hooked, Hooked-end, Twisted, Crimped, end-hooked, straight \\
\hline Aspect ratio & $29-81$ \\
\hline Compressive strength (Mpa ) & $0-86.6$ \\
\hline Tensile strength (Mpa ) & $0-12.3$ \\
\hline Shear strength (Mpa) & $0-11.58$ \\
\hline
\end{tabular}

\section{NEW MULTIPLE VIABLE EQUATIONS}

The new empirical is formula for calculation of mechanical strength (compressive, tensile and shear) based on multiple variable regressions such as percentage of steel fiber, water cement ratio, aspect ratio, percentage of cement and aggregate. For the derivation of formula more than 50 experimental work data [2-15] is used to develop the four different equations. The basic equation for multiple regressions is:

$$
\mathrm{y}=\mathrm{b}_{0}+\mathrm{bx}_{1}+\mathrm{bx}_{2}+\mathrm{bx}_{3} \ldots . .+\mathrm{bx}_{\mathrm{n}}
$$

Based on Equation 1 the general equation for compressive, tensile and shear of FRC are:

\subsection{Compressive strength}

Three equations are developed empirical equation of SFRC by using different properties as shown in above Table 1.

$$
\begin{aligned}
\sigma_{\text {Compressive }}= & 100.2257+2.913508\left(\mathrm{~V}_{\mathrm{t}}\right)-91.0231(\mathrm{w} / \mathrm{c})- \\
& 0.05945(\mathrm{C}) \\
\sigma_{\text {Compressive }}= & 89.7373202+3.052725\left(\mathrm{~V}_{\mathrm{t}}\right)-107.3881976 \\
& (\mathrm{w} / \mathrm{c})-0.094657534(\mathrm{P}) \\
\sigma_{\text {Compressive }}= & 45.04102217+2.423448276\left(\mathrm{~V}_{\mathrm{t}}\right)- \\
& 0.740973892(\mathrm{P})
\end{aligned}
$$

\subsection{Tensile strength}

Tow equations are used data as table 1 to develop the below equation:

$\sigma_{\text {Tensile }}=0.53325\left(\mathrm{~V}_{\mathrm{t}}\right)-5.990202055+0.026481267(\mathrm{C})$ 0.0085273947 ( P )

$$
\begin{aligned}
\sigma_{\text {Tensile }}= & 5.49576127+2.31024379\left(\mathrm{~V}_{\mathrm{t}}\right)- \\
& 0.036534039 *(\mathrm{P})
\end{aligned}
$$

\subsection{Shear strength}

Tow equation are used to developed shear strength in SFRC are given below:

$$
\begin{aligned}
\sigma_{\text {Shear }}= & 4.02484485\left(\mathrm{~V}_{\mathrm{t}}\right)-3.464421798-0.112666667(\mathrm{P})+ \\
& 0.015061828 *(\gamma) \\
\sigma_{\text {Shear }}= & 3.386443374+0.616343137\left(\mathrm{~V}_{\mathrm{t}}\right)+ \\
& 0.002936231(\mathrm{w} / \mathrm{c})
\end{aligned}
$$

Where

$$
\begin{aligned}
& \sigma=\text { Compressive of SFRC } \\
& V_{t}=\text { percentage of Steel fiber } \\
& \text { W/c = Water cement ratio } \\
& C=\text { Cement content } \\
& \rho=\text { Aspect ratio } \\
& \gamma=\text { Aggregate content }
\end{aligned}
$$

\section{RESULTS AND DISCUSSION}

The percentage of steel fibre is active to the concrete in different parameter such as compressive strength, tensile strength and shear strength with respect to different variables such as; aspect ratio, water cement ratio and cement content. The below charts shown the effective of SFRC strength in the concrete by using developed statistical relationships between them.

\subsection{Compressive strength \\ 4.1 Compressive strength}

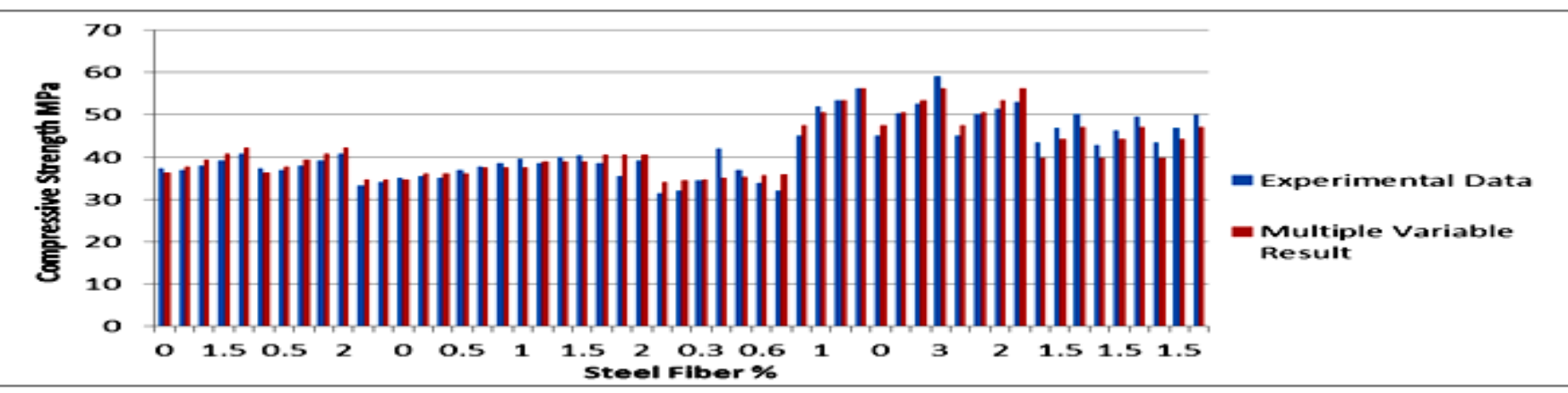

Fig.2: Relationship between experimental data and multiple variable results by using Equation 2 
Fig. 2 shown the Experimental data and multiple variable result by using Equation 2 for compressive strength. In fact, the
Multiple Variable results were close in almost all the Experimental data results. The multiple $\mathrm{R}$ and $\mathrm{R}$ square are 0.946 and 0.895 .

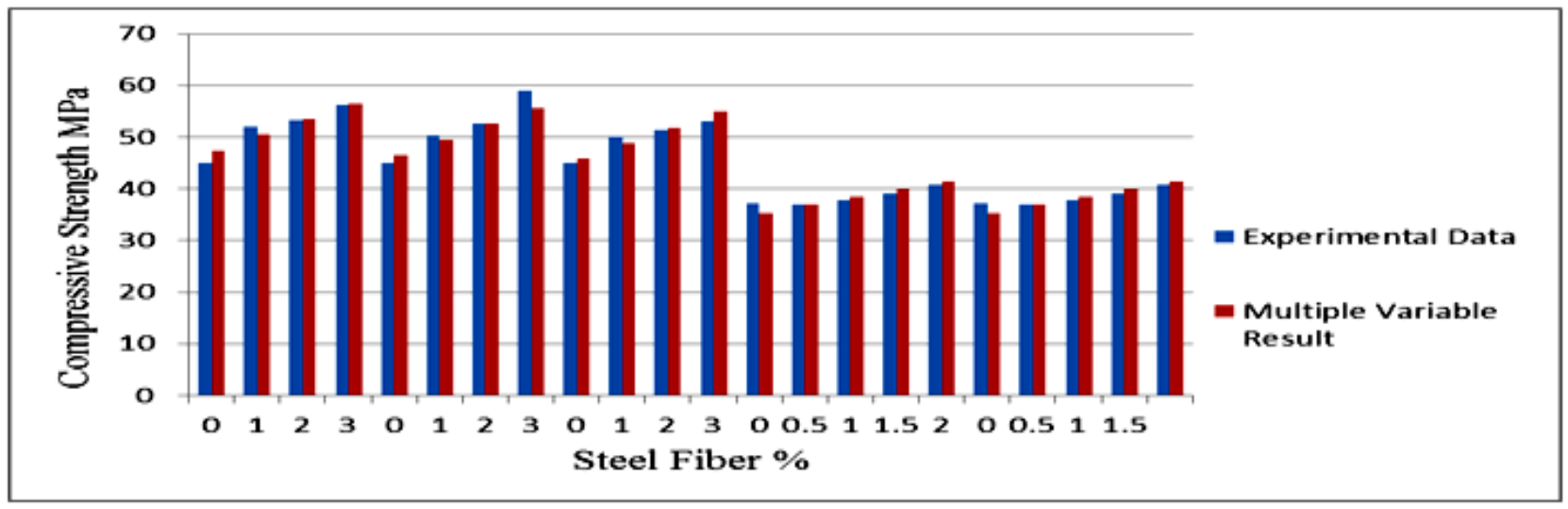

Fig.3: Relationship between experimental data and multiple variable results by using Equation 3

The above figure is shown the Experimental data and multiple variable result by using Equation 3.The result shows that Multiple Variable Result is close to Experimental Data and the multiple $\mathrm{R}$ and $\mathrm{R}$ square are 0.982 and 0.965 . The highest different error between them is 0.4 and it is small value.

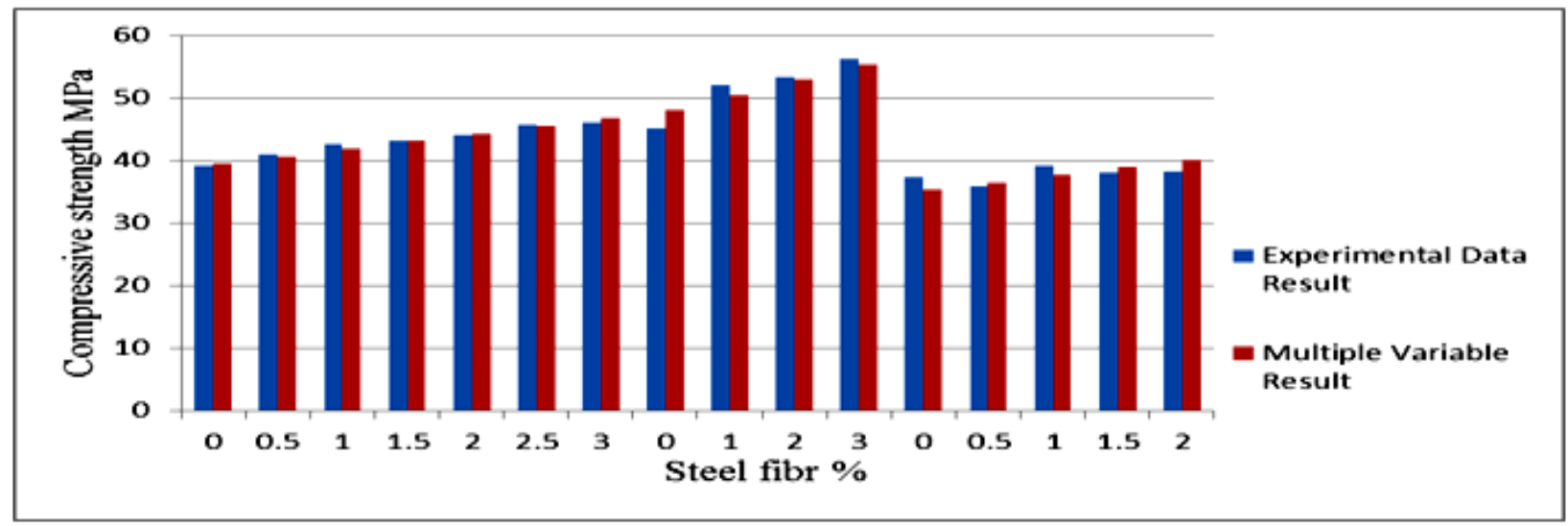

Fig. 4: Relationship between experimental data and multiple variable results by using Equation 4

Fig. 4 shows the relation between steel fiber and compressive strength by using Equation 5. Almost both results fits together with compressive strength and percentage of steel fiber relationship. The highest difference of compressive strength between Multiple Variable and Experimental data results was by $2.917 \mathrm{MPa}$ at $0 \%$ steel fiber. As a result, Multiple Variable equation is a useful equation to predict the experimental data without doing the experiment. The multiple $\mathrm{R}$ and $\mathrm{R}$ square are 0.977 and 0.955 .

\subsection{Tensile strength}

The relation between steel fiber and tensile strength with respect of parameters which are cement content and aspect ratio is shown in Fig. 6. The results gotten from Multiple Variable equation were compared with the Experimental data result to show the accuracy of using that equation. In fact, the Multiple Variable results were close in almost all the Experimental data results. Accordingly, the multiple R and R square are 0.9 and 0.8 . 


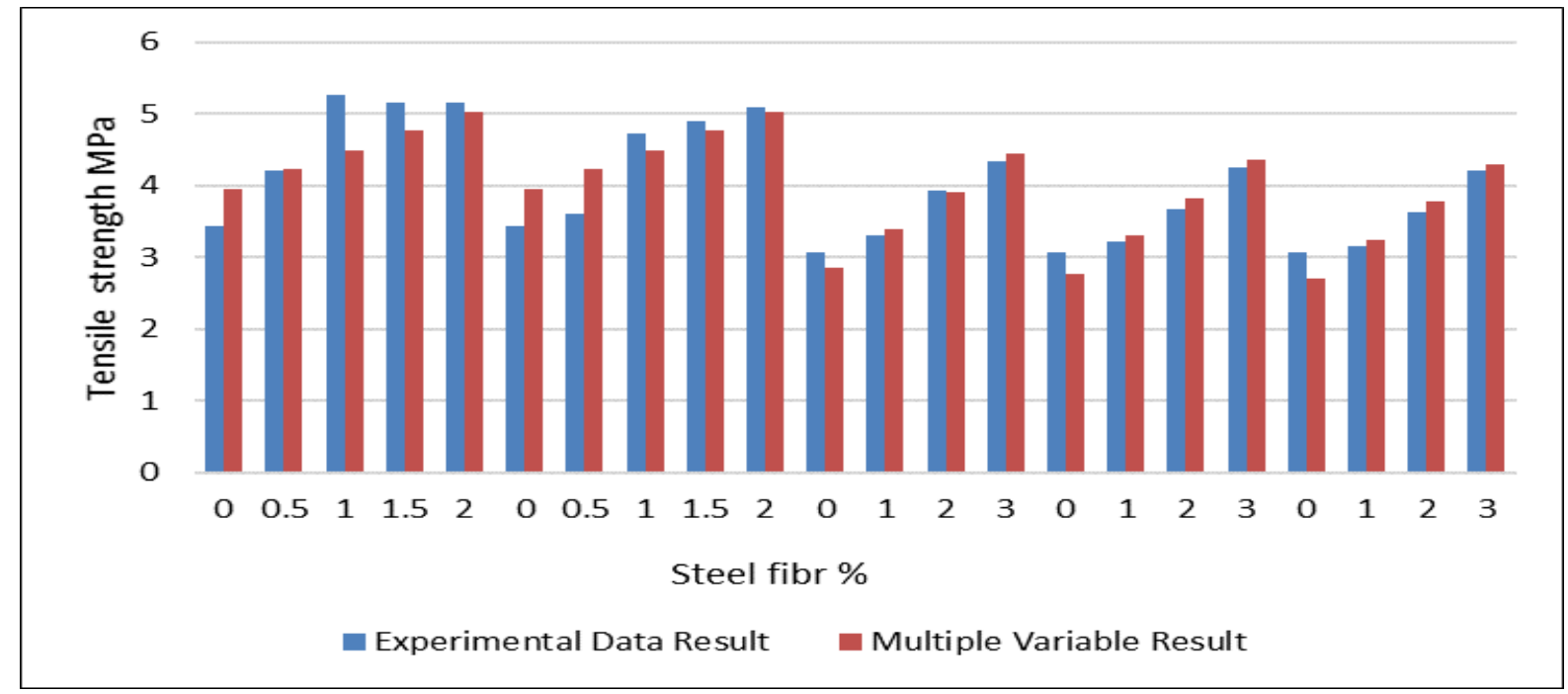

Fig.5: Relationship between experimental data and multiple variable results by using Equation 5 .

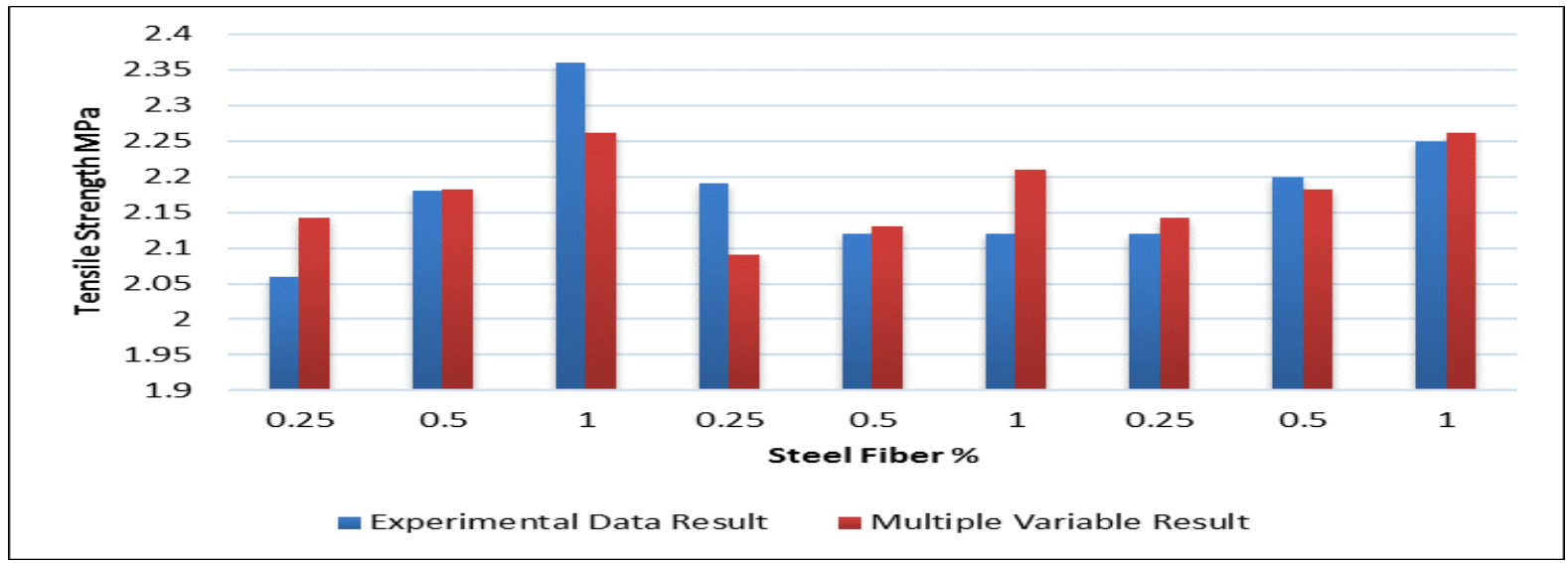

Fig.6: Relationship between experimental data and multiple variable results by using Equation 6

In Fig. 6, the relation between experimental data and multiple variable results by using Equation 6. Multiple Variable results were close in all the Experimental data results. The highest difference of tensile strength between Experimental data and Multiple Variable results was $0.099 \mathrm{MPa}$ at coordinates $(0.25 \%, 2.19 \mathrm{MPa})$ and $(0.25 \%, 2.090 \mathrm{MPa})$ respectively. The multiple $\mathrm{R}$ and $\mathrm{R}$ square are 0.88 and 0.78 .

\subsection{Shear strength}

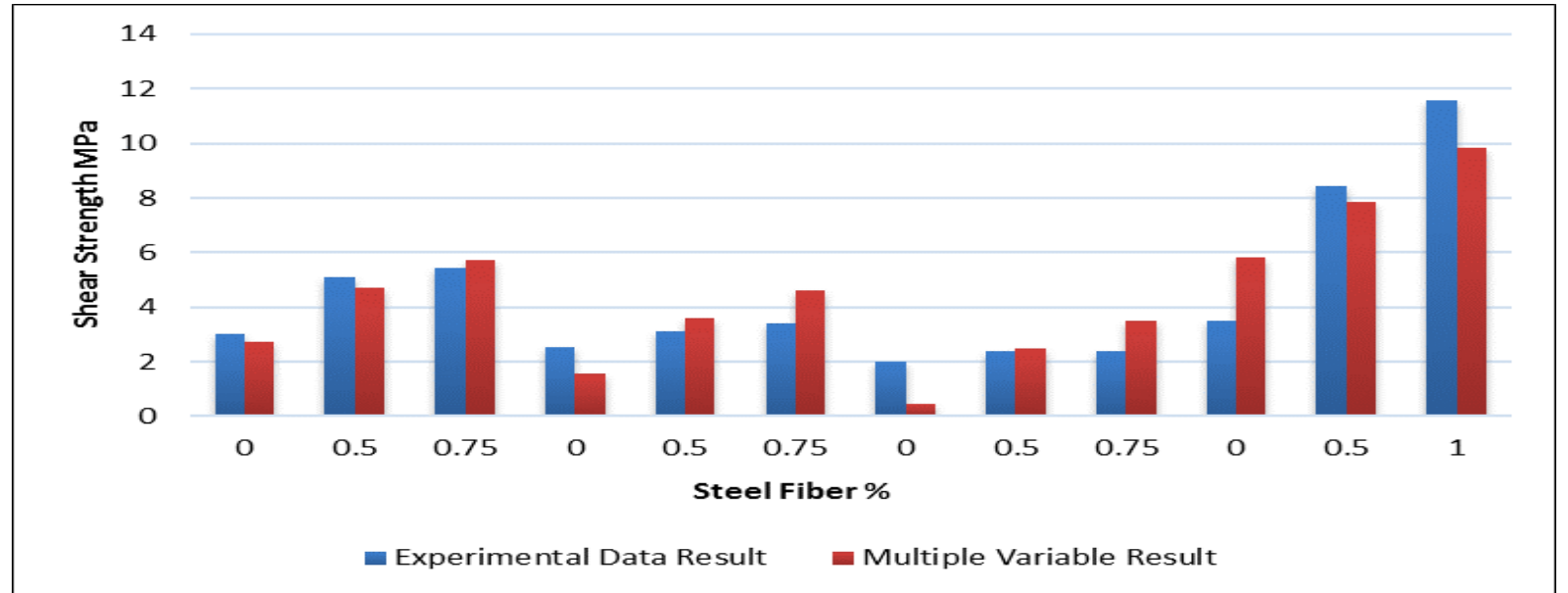

Fig.7: Relationship between experimental data and multiple variable results by using Equation 7

The relation between steel fiber and shear strength with respect of fixed parameters which are aggregate content and aspect ratio is shown in Figure 8. The multiple $\mathrm{R}$ and $\mathrm{R}$ square are 0.91 and 0.83 . It shows a good relationship between them. 


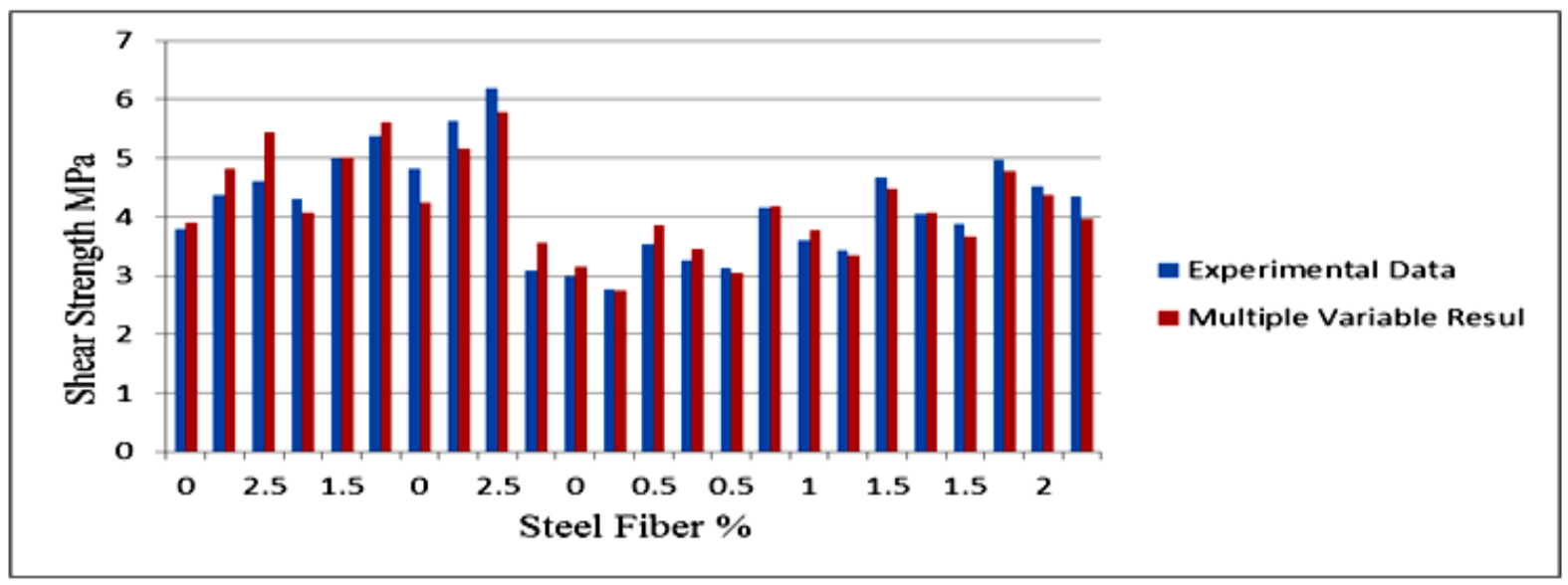

Fig.8: Relationship between experimental data and multiple variable results by using Equation 8

The relation between experimental data and multiple variable results by using Equation 8 is shown in figure.8. The multiple $\mathrm{R}$ and $\mathrm{R}$ square are 0.92 and 0.86 . It shows a good result.

\section{COMPARISON}

\subsection{Compressive strength}

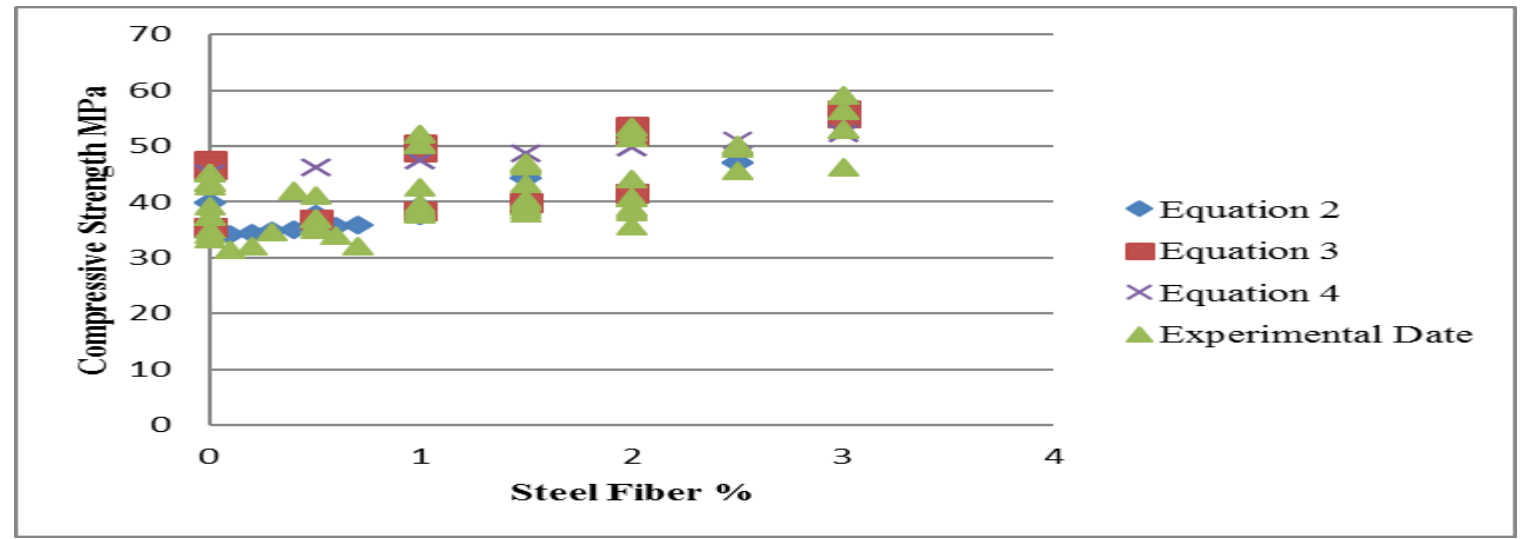

Fig. 9: Relationship between Experimental data and Equation 2, 3and 4.

Fig. 9 shown the Experimental data and Equation 2, 3 and 4. Equation 2and 3 gave very close values of compressive strength than Equation 4 in the different percentage of steel fiber. The different error is 0.6. In fact, Equation 3 was close in almost all the Experimental data result.

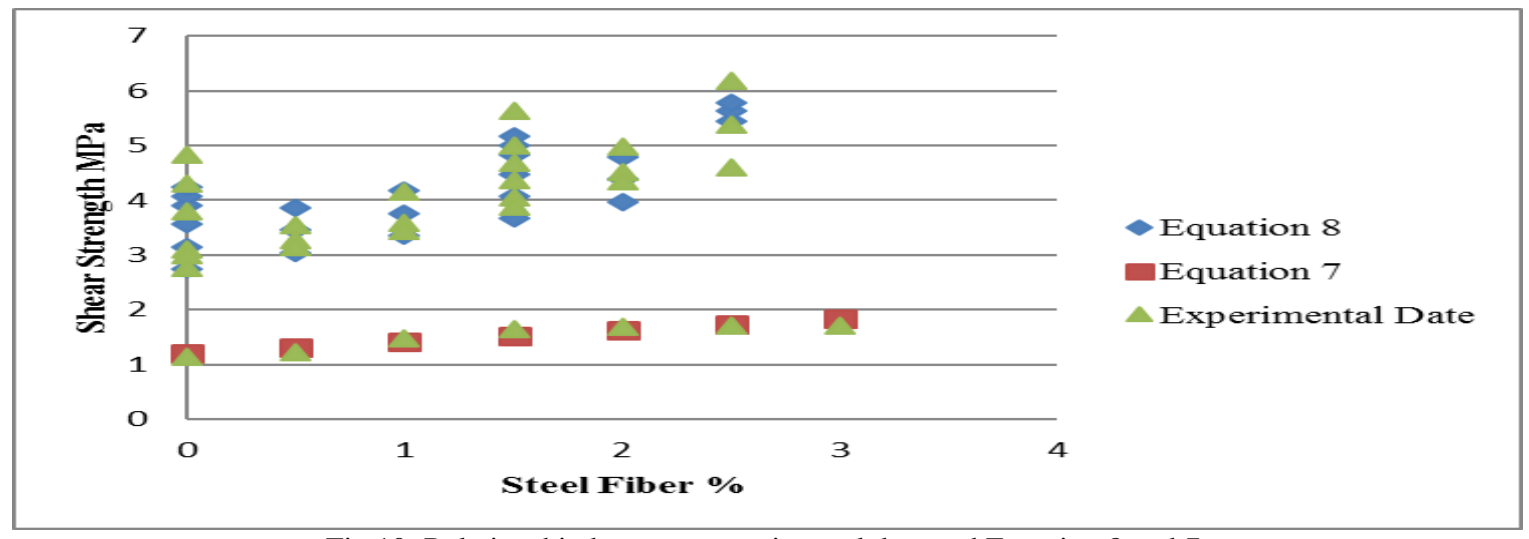

Fig.10: Relationship between experimental data and Equation 8 and 7.

Fig. 10 shown the relationship between experimental data and equations 7 and 8 . All results gave very close values of shear strength in different percentages of steel fiber. The highest different error between them is 0.3 and it is small value. As a result, clearly we can see that Equation 7 gave very close values to shear strength than Equation 8. 


\subsection{Tensile strength}

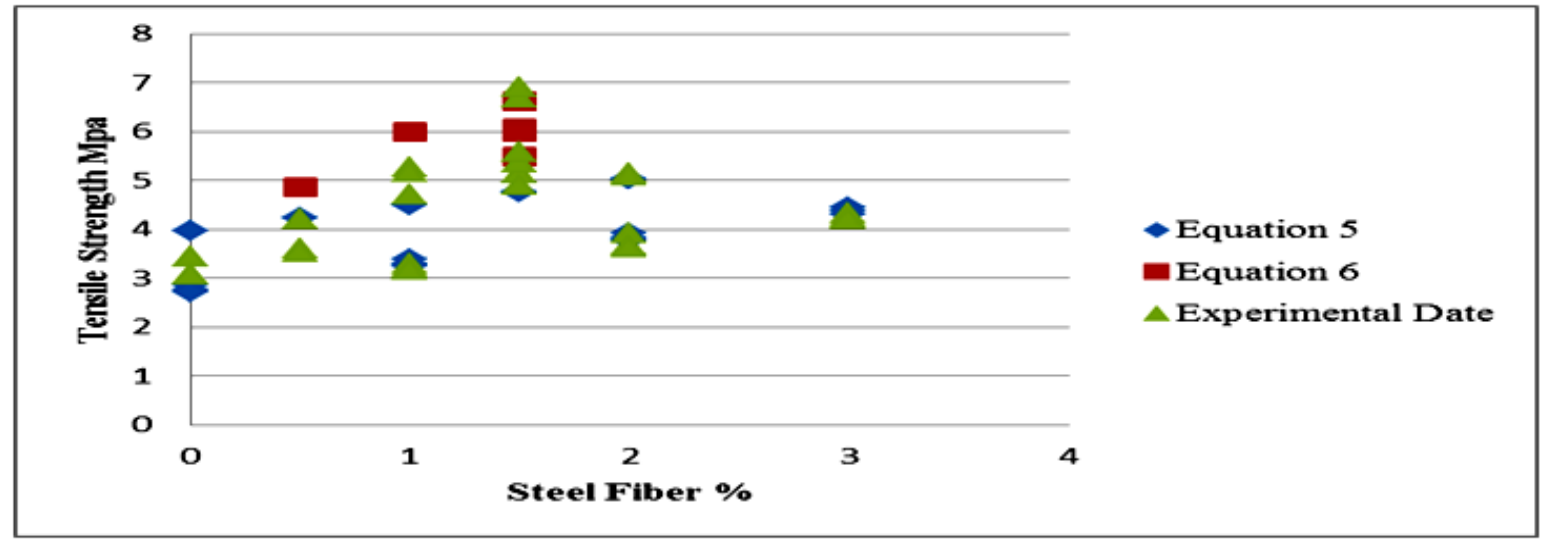

Fig. 11: Relationship between Experimental data and Equation 5and 6

The above Fig. 11 shown the Relationship between Experimental data and Equation 5 and 6. Clearly we can note that Equation 5 has very close result to Experimental Date that Equation 6 in different percentage of tensile strength. The different error between them is 0.9 .

\section{CONCLUSIONS}

In this paper multiple variable empirical equation has been developed to calculate compressive strength, tensile strength, and shear strength of steel fiber reinforced concrete (SFRC) based on percentage of Steel fiber, Water cement ratio, Cement content, Aspect ratio, and Aggregate content. It is found that all developed equation shows good relation with experimental data. Based on results and comparison it is recommended to use newly developed equation for prediction of compressive, tensile, and shear strength of SFRC within limitations mentioned in table1.

\section{REFERENCES}

[1] Harsh. Steel Fiber Reinforced Concrete: An Analysis. Meridian : The Inquisitive Meridian, 2013.

[2] Belgaraâ, M. Beddar and L. OPTIMIZING OF STEEL FIBER REINFORCED. Canada : M'sila University, 2003.

[3] Technical Manual . Radmix. 2009, www.Radmix.com, pp. 26-28.

[4] FOUAD, FAISAL. Properties and Applications of Fiber Reinforced Concrete. Saudi Arabia : King Abdulaziz University, 1990.

[5] Experimental Study on Steel Fiber Reinforced Concrete for M-40 Grade. A.M.Shende et.al. 2012, J.L.C.C.E, pp. 34-48.

[6] DISCRETE CRACK MODEL OF STEEL FIBRE REINFORCED CONCRETE MEMBERS. Adas Meskenas, Darius Ulbinas. 2011, Vilnius Gediminas technical university, pp. 1-5.

[7] Simplified Mix Design Procedures for Steel Fibre Reinforced Self Compacting Concrete. Abibasheer Basheerudeen and Sivakumar Anandan. 2015, ENGINEERING JOURNAL, pp. 1-16.

[8] MONDO, ELEONORA. Shear Capacity of Steel Fibre Reinforced Concrete Beams without Conventional Shear Reinforcement. Sweden : Royal Institute of Technology (KTH), 2011.

[9] Behaviour and Analysis of Steel Fibre-Reinforced Concrete under Reversed Cyclic Loading. Luo, Jun Wei. 2014, University of Toronto, pp. $18-84$.

[10] Performance of steel fiber on standard strength concrete in compression. Prashant Y.Pawade et al. 2011, INTERNATIONAL JOURNAL OF CIVIL AND STRUCTURAL ENGINEERING, pp. 480 - 489.

[11] Behaviour and Analysis of Steel and Macro-Synthetic Fibre Reinforced Concrete Subjected to Reversed Cyclic Loading: A Pilot Investigation. Carnovale, David Joseph. 2013, University of Toronto, pp. 9-130.
[12] Experimental Study on Crimped Steel Fiber Reinforced Concrete Deep Beam in Shear. Balgude, Vikram Vijaysinh. 2014, IOSR Journal of Mechanical and Civil Engineering (IOSR-JMCE), pp. 154 - 203.

[13] Shear strength of SFRC Beam with stirrups . Yoon- keun et.al. 2014, ACL Strucatural Journal , pp. 500- 530.

[14] EXPERIMENTAL INVESTIGATION ON SHEAR STRENGTH OF SFRC BEAMS REINFORCED WITH LONGITUDINAL TENSION STEEL REBARS. Londhe, R.S. 2010, ASIAN JOURNAL OF CIVIL ENGINEERING (BUILDING AND HOUSING) VOL, pp. 385-395.

[15] Evaluation of mechanical properties of steel-fibre-reinforced concrete exposed to high temperatures by double-punch test. Jihwan Kim et al. 2015, ELSEVIER, pp. 182-191. 